January 1985

\title{
The Double Blind Gordian Knot
}

John Matt Dorn, MD

Thomas Jefferson University Hospital

Follow this and additional works at: https://jdc.jefferson.edu/jeffjpsychiatry

Part of the Psychiatry Commons

Let us know how access to this document benefits you

\section{Recommended Citation}

Dorn, MD, John Matt (1985) "The Double Blind Gordian Knot," Jefferson Journal of Psychiatry. Vol. 3 : Iss. 1 , Article 13.

DOI: https://doi.org/10.29046/JJP.003.1.011

Available at: https://jdc.jefferson.edu/jeffjpsychiatry/vol3/iss1/13

This Article is brought to you for free and open access by the Jefferson Digital Commons. The Jefferson Digital Commons is a service of Thomas Jefferson University's Center for Teaching and Learning (CTL). The Commons is a showcase for Jefferson books and journals, peer-reviewed scholarly publications, unique historical collections from the University archives, and teaching tools. The Jefferson Digital Commons allows researchers and interested readers anywhere in the world to learn about and keep up to date with Jefferson scholarship. This article has been accepted for inclusion in Jefferson Journal of Psychiatry by an authorized administrator of the Jefferson Digital Commons. For more information, please contact: JeffersonDigitalCommons@jefferson.edu. 


\section{BOOK REVIEW}

\section{THE DOUBLE BLIND GORDIAN KNOT}

\section{DIFFERENTIAL THERAPEUTICS IN PSYCHIATRY: THE ART AND SCIENCE OF TREATMENT SELECTION \\ A. Frances, M.D., J. Clarkin, Ph.D., \& S. Perry, M.D. New York: Brunner/Mazel, 1984 395 pp., $\$ 30.00$}

\section{JOHN MATT DORN, M.D.}

We work in the dark - we do what we can - we give what we have. Our doubt is our passion and our passion is our task. The rest is the madness of art.

\section{H. James}

Medicine, unlike psychiatry, often seems crisply linear. A diagnosis, once it is made, usually implies not only an etiology, but a course of treatment as well. "For most common medical problems, the course of action has been well defined on the basis of expert medical opinion; the territory is familiar and requires no special effort at analysis. Indeed, much clinical instruction, whether on the management of a suspected urinary traction infection, hypertension or acute pulmonary edema, is based, at least implicitly, on choices dictated by detailed medical protocols. For several conditions such protocols have been explicitly converted into flow charts for use in patient care" (1).

Psychiatry, by contrast, often seems unbearably murky. Diagnoses themselves are frequently matters of controversy. "Beginners in psychiatry sometimes play the game of presenting one case to several seniors. The first teacher picks up depressive themes, a second oedipal ones, and a third the way incident after incident points to passive homosexual or narcissistic traits. If the issue is classic diagnosis, a few paranoid features may be underlined by one observer or catatonic signs by another, and either allowed to dominate the naming. There are usually enough disagreements to confound the scientists and send the frightened back to chemistry" (2).

Similarly, treatment decisions are often dominated by partisan reasoning. Of course practitioners are more likely to recommend treatments they are familiar with. The sectarian nature of psychiatry, however, makes it likely that alternative and

Dr. Dorn is a fourth-year resident. 
equally valid modalities will be overlooked. As a result, the patient may not get the treatment he needs, but as L. Havens suggests, ". . . the one treatment that the doctor dispenses. Today we have therapists who give drugs and electric treatments or deconditioning or psychoanalysis or family therapy, no matter who rings the bell, like mad surgeons with one operation for everyone." Havens goes on to suggest that the source of this factiousness may be related to the nascent state of psychiatry: ". . because psychiatric development is at a more uncertain stage than that of medicine or surgery, psychiatrists experience these decisions as dilemmas among which our incomplete understanding hesitates" (2).

Other reasons offered for the reluctance to pursue alternative treatments include the press of clinical exigencies and the fear of premature closure (by third-party payers). Whatever the reason, there can be no doubt that differential treatment planning is the Achilles' heel of psychiatric education and that Differential Therapeutics in Psychiatry is a unique and exciting attempt to address this problem. As is stated in the introduction:

Mental health trainees typically receive little education in the principles and practice of choosing a treatment modality. Too often treatment assignments are made routinely, based on customary practices, and with little discussion. Trainees are frequently asked to recommend a treatment from among a variety of treatment alternatives that they themselves have never had occasion to perform. Moreover, the assumptions behind recommendations may remain unclear, unspecified, and or uncertain validity. In our experience, the trainee and supervisor are likely to spend the bulk of their time together discussing phenomenology or psychodynamics. The discussion about the choice of treatment, if it comes up at all, is often tagged on to the waning moments and is dealt with as a practical necessity rather than an important part of the teaching.

The authors themselves represent the balance they seek to impart. "One author (AF) is a psychiatrist and psychoanalyst who works primarily with outpatients; another author (JC) is a more behaviorally oriented psychologist and family therapist; and the third (SP) is a psychoanalytically trained psychiatrist whose main clinical area is in a general hospital working with physically ill patients."

Using illustrative case histories, the authors explore four parameters of psychiatric treatment: setting, format, orientation, and duration and frequency. In each case alternative modalities are discussed in detail, followed by the actual course of treatment. The great strength of the authors' presentation lies in their clear and concise analysis of existing clinical data. An example of their self-effacing honesty is evident in the following summary:

We concluded our review of the research regarding duration and frequency of treatment with the same caution with which we began this chapter. Our current knowledge about time factors in psychotherapy is very limited and confounded by the many variables influencing how intense and how long any treatment should be. Nevertheless, this discussion of $\mathrm{Mr}$. $\mathrm{H}$ might help 
remind us that decisions about frequency and duration must be made throughout any treatment and cannot simply be deferred because they are too difficult or complex. Further research will, no doubt, heighten this awareness and document that the handling of duration and frequency can have a profound effect on the quality and quantity of therapeutic results.

In successive chapters, the authors address the issues of somatic treatment, combination treatments, and "no treatment" as therapeutic alternatives. By far my favorite was the chapter on "no treatment." In my experience the idea of "no treatment" has never been presented as a serious alternative. ("He keeps coming in, doesn't he? You must be doing some good.") Jokingly I have sometimes wished that psychiatry could borrow the concept of the "inoperable patient." The authors present convincing evidence that "no treatment" may be a legitimate, positive treatment alternative. They summarize their opinions as follows. "No treatment may:

1) protect the patient from iatrogenic harm, especially by interrupting a sequence of destructive treatment;

2) protect the patient from wasting time, effort, and money;

3) delay therapy until a more propitious time;

4) protect and consolidate gains from previous treatments;

5) provide the patient an opportunity to discover that he can do without treatment; and

6) avoid a semblance of treatment when no effective treatment exists."

The remaining chapters deal with research and treatment planning, clinical evaluation for treatment selection, psychological testing for treatment selection, and teaching of differential therapeutics. The chapter on clinical evaluation for treatment selection is worth the price of admission. Indeed this is one of the most clinically relevant and useful texts I have read. Particularly useful was the authors' explanations of and criticisms about different psychological tests.

In contrast I have no useful criticism to offer of the style or content of Differential Therapeutics in Psychiatry. I run the risk of hyperbole by saying that this book should be mandatory reading for all psychiatric residents. More importantly it is the process of differential therapeutics that must be incorporated into psychiatric education. In this regard Differential Therapeutics in Psychiatry represents the beginning of a new perspective in psychiatry. Perhaps when all is said and done Nolan D. C. Lewis will be right in saying that "the right techniques with the wrong therapist will do less good than the wrong technique with the right therapist." Regardless, we will no longer be mad surgeons with one operation for everyone, but enlightened therapists whose discretion is as sharp as our technique.

\section{REFERENCES}

1. Schwartz WB: Decision analysis, a look at the chief complaints. NEJM 300: 556-559, 1979

2. Havens L: Approaches to the Mind. Boston, Little Brown \& Co., 1973 